\title{
AVICENA: Médico árabe medioeval
}

\author{
JOAQUÍN OCAMPO \\ Departamento de Historia y Filosofía de la Medicina. \\ Facultad de Medicina de la Universidad Nacional Autónoma de México
}

\begin{abstract}
RESUMEN
En este trabajo se hace una reseña de la vida y obra del médico árabe medioeval Avicena, uno de los más importantes de su cultura y época. Previa justificación del artículo, se hace referencia al contexto, el hombre y su obra, seguida de un comentario.
\end{abstract}

Palabras clave: Avicena; Historia de la Medicina Medieval; Ciencia, Historia; Medicina Arabica.

AVICENA : Arabian Physician of Middle Ages.

SUMMARY

Avicena, a physician and philosopher of the Middle Ages, is considered one of the most important thinkers of Arabian medicine. After a paper justification, the author appoints the context, life and work of Avicena. Later he appoints a commentary on particular.

Key words: Avicena, History of Medicine, Medieval; Science, History; Medicine, Arabic.

\section{INTRODUCCIÓN}

En ocasiones la investigación biomédica o médicoclínica limita que el investigador vaya más allá de la información que fundamente su estudio, pruebe sus hipótesis o estructure sus conclusiones. No permite hacer un alto y reflexionar acerca de la forma cómo el hombre se ha explicado su entorno.

A pesar de uno mismo, la investigación absorbe de tal manera la atención que con frecuencia se pasa por alto que los conocimientos que hoy se desea ampliar y profundizar no surgieron de la nada, sino que constituyen el resultado de la evolución del pensa-

Correspondencia:

Dr. Joaquín Ocampo Marlínez

Calle Orleans Num. 14 Lomas Estrella.

C. P. 09890 . México D. F. miento, desde que se manifestó como una característica específicamente humana (').

La medicina, por ejemplo, no siempre tuvo un carácter científico, y no por ello careció de nociones y estrategias para tratar a los enfermos, logrando beneficios incuestionables que permitieron la supervivencia de la humanidad durante miles de años antes de la aparición de la práctica médica científica (').

¿Cómo fue esto posible? La historia de la ciencia, de la filosofía y de la medicina, da la respuesta de diversas formas.

Una de ellas es el conocimiento de la vida y aportaciones de aquellos que sin tener la aureola de la santidad o el heroísmo, trataron a los enfermos a través de la cosmovisión propia de su época, herencia ancestral asimilada y transformada que fructificó en diversas concepciones sobre el fenómeno salud-enfermedad y en nuevos enfoques para el diagnóstico y el tratamiento de los pacientes ('). 
Esos médicos a la par que procuraban la salud de los enfermos, reflexionaban sobre sus éxitos y fracasos, asentando sus ideas y experiencias en obras ya clásicas. afortunadamente conservadas en el idioma original o en traducciones, en muchas bibliotecas del mundo.

Como es de suponer, este tipo de información amplía la visión y la cultura del investigador. El estudio de la vida y obra de los médicos antiguos no tiene obviamente el propósito de poner en práctica procedimientos y métodos ya superados en su mayoría, o rendir culto a su personalidad ('). La meta es enriquecer, a través de nuestra reflexión, la dimensión humanística que subyace en toda investigación de la realidad, porque en el grado en que se conoce y se analiza cada aportación del pasado, se valora y ubica cada logro del presente como parte de una secuencia interminable de ideas y explicaciones que ha sido el sustento de la práctica médica científica y no científica (').

Entre un sinnúmero de médicos del medioevo, forma parte de la memoria histórica el célebre médico árabe Abu Ali al-Hussein ibn Abdallah ibn Sina, más conocido como Avicena cuya obra médica fue difundida durante más de ochocientos años en muchas escuelas del mundo.

La educación médica española, por ejemplo, se inició en la Universidad de Salamanca el año de 1252. En ella se estableció la enseñanza de la obra médica de Avicena, porque se consideraba que era más consistente que la de Galeno $\left({ }^{2}\right)$. Esta universidad sirvió de modelo para la formación de los médicos en las colonias españolas.

En 1551, Carlos V fundó la Universidad de San Marcos de Lima, Perú, y la Real y Pontificia Universidad de México $\left({ }^{2}\right)$. La primera continua como la actual Universidad Nacional Mayor de San Marcos de la República del Perú, y la segunda es el más antiguo antecedente de la Universidad Nacional Autónoma de México.

\section{EL CONTEXTO}

El pensamiento del pueblo árabe se enriqueció e integró al saber universal a partir de la expansión del Islam en el siglo VII de nuestra era. Un mercader llamado Mahoma (570-630 d. C.) fundó la religión islámica (Islam significa "sumisión a Alá"). Según sus prédicas, había sido escogido por Alá (Dios), para difundir su palabra al pueblo árabe y al mundo. Estas ideas religiosas quedaron contenidas en el texto sagrado -aún vigente- de los musulmanes o islámicos (los sometidos), llamado Corán ( $\left.{ }^{3.4}\right)$.

A la muerte de Mahoma, los adeptos a la nueva religión organizaron la llamada "guerra santa" ( Jihad), que tuvo como principal objetivo divulgar el Islam a todo el mundo conocido en esa época. De esta manera, dominaron todo el territorio que hoy corresponde a los países de Arabia, Siria, Irán, Irak, el norte del Magreb (Túnez, Marruecos y Argelia), así como el sur de España y toda el Asia central hasta el río Indo $\left({ }^{3.4}\right)$.

Su sólido gobierno y su fuerte convicción religiosa lograron esta expansión, que se caracterizó por una actitud moderada hacia los pueblos conquistados y su tolerancia con las múltiples corrientes dentro de sus comunidades, abriendo el camino hacia la integración de pueblos y culturas. Así, el Islam empezó a modificar la antigua estructura social de Asia occidental y Egipto, y en las antiguas culturas de tradición griega y persa fueron incorporándose elementos árabes $\left({ }^{4}\right)$.

A su vez, los árabes quedaron asombrados con la forma de pensar y ver el mundo de los pueblos sometidos. La asimilación de estas nuevas concepciones posibilitó la introducción del sistema y el método en el pensamiento árabe, gracias a su marcado interés por traducir los textos grecolatinos antiguos sobre diversas áreas como astronomía, matemáticas, teologia, derecho, filosofía y medicina $\left({ }^{3}\right)$.

Con relación al médico-filósofo Avicena, a este contex to histórico-social debe agregarse el que existía particularmente en Persia (Irán), de donde era originario, y que se vio ampliamente influido por la tradición griega y árabe antes que él naciera. En el siglo V de nuestra era ocurrió que una secta de cristianos heréticos conocida como nestorianos, fue desterrada de diversas ciudades por el cuestionamiento que hacía al cristianismo, siendo aceptada finalmente en la ciudad persa de Gundishapur ${ }^{(5.6}$ ).

Esta secta tenía amplios conocimientos de los textos neoplatónicos, aristotélicos y de la medicina hipocrático-galénica. En esta ciudad establecieron un centro para la enseñanza de la medicina que inició una tradición en la antigua Persia y que fue enriquecida con la fundación, en el siglo VII, de una academia hipocrática en esa ciudad $\left({ }^{5}\right)$. 
Cabe recordar, por otra parte, que la Persia del siglo $X$, en que nace Avicena, se caracterizó por un fenómeno nacional al que se ha denominado Renacimiento persa y que consistió básicamente en la acción de algunas dinastías locales que revivieron el sentimiento y la cultura, contribuyendo a una independencia cultural de Persia con respecto al resto del mundo árabe, sin apartarse totalmente del contexto islámico.

Algunos gobernantes de estas dinastías determinaron muchos acontecimientos en la vida social y política de Avicena, sobre todo Alá el Dawleh quien fue protector de intelectuales así como de teólogos y juristas. Por otra parte, la efervescencia intelectual árabe que durante mucho tiempo tuvo como centro a Bagdad, se desplazó durante el siglo $\mathrm{X}$ hacia Persia y otras zonas orientales, debido a que en aquella ciudad había disminuido el interés por lo extranjero $y$, por lo tanto, por el pensamiento grecolatino $\left({ }^{7}\right)$.

En este clima intelectual y social se desarrolla Avicena, uno de los médicos más importantes del mundo árabe medioeval.

\section{EL HOMBRE}

Se sabe de la vida de este personaje, gracias a la autobiografía que se enriqueció con los testimonios escritos de su amigo y discípulo Al-Juzjani.

Conforme a esta información, Avicena nació en agosto del año 980 d. C. en la villa persa de Kharmaitan o bien en Afsina, ambas cercanas a la importante ciudad de Bukhara.

Era hijo del gobernador de su pueblo natal y desde pequeño dio muestras de su gran talento. A los diez años ya conocía el Corán, que además de su contenido religioso, menciona algunas reglas para una vida higiénica e indicaciones dietéticas. A Mahoma, fundador del Islam, se le atribuyen frases como: "si un enfermo pide una cosa hay que dársela"; "sólo hay dos ciencias, la teología para la salvación del alma y la medicina para la salvación del cuerpo".

El primer contacto de Avicena con el saber occidental fue la lectura de las obras de Porfirio, uno de los más importantes filósofos neoplatónicos (el neoplatonismo plantea la existencia de la inmortalidad del alma y la creencia de que uno es el mundo de las ideas y otro el mundo de los objetos). También influyeron de manera importante Euclides, el célebre geómetra, y Claudio Ptolomeo, astrónomo y géografo que afirmaba que la Tierra era el centro del universo. A los diecinueve años leyó muchas obras de medicina, área que siempre se le facilitó.

Estudió también el pensamiento aristotélico, base de todo el pensamiento occidental de nuestro tiempo, influyendo notablemente en su obra. Sirvió como consejero y médico de varios gobernantes persas, lo cual le dio acceso a numerosos textos de medicina y filosofía griega y latina traducidas al árabe, existentes en sus bibliotecas $\left({ }^{7}\right)$.

Era hombre de buena presencia y en cuanto a sus hábitos, era muy activo, se dice que además de su inquietud intelectual, era afecto al buen vino y a las relaciones sexuales frecuentes $y$, aunque en sus textos recomienda la moderación para llevar una vida sana y duradera, se menciona que en una ocasión se le hizo un comentario acerca de sus pasiones excesivas, a lo que respondió diciendo que prefería vivir intensamente pocos años, que llevar una vida aburrida por mucho tiempo $\left({ }^{7}\right)$.

Dado que hablaba el persa, su conocimiento del árabe no era profundo. Al respecto, en una ocasión manifestó su punto de vista sobre un problema lingüístico difícil. Uno de los eruditos allí presente, lo criticó diciendo que a pesar de ser un sabio y un filósofo, no conocía el árabe como para acaparar la atención de la concurrencia. Este comentario lastimó el amor propio de Avicena pero lo estimuló a profundizar sobre literatura y gramática árabe $\left({ }^{7}\right)$.

A los tres años de aquel suceso, escribió un volumen con poemas y ensayos tratando de imitar el estilo de algunos poetas y literatos árabes famosos. Mostró el volumen a quien le había hecho aquella crítica, instándolo a que manifestara quién era el autor, a lo que el sabio respondió que seguramente correspondía a una de las glorias de la literatura árabe. Esta respuesta causó una gran satisfacción a Avicena y mucha gracia a los allí presentes.

Avicena nunca salió de Persia aunque constantemente cambiaba de residencia, lo cual ha sido motivo de intriga para sus biógrafos puesto que en su autobiografía no da las razones de ello, quizá de una manera intencional. En Gurgan, abrió una escuela pública donde comenzó la redacción de su texto más famo- 
so, el Canon de Medicina. Ahí también escribió una obra de Lógica.

En el ultimo viaje que hizo en su vida، acompañando a su mecenas el gobernante Alá el Dawleh ya mencionado, sufrió un cólico severo. Por la necesidad de una rápida curación, se administró varias dosis de los medicamentos que existía para el caso. Siguió atendiéndose él mismo, pero cada vez que alcanzaba alguna mejoría volvía a recaer debido a que continuaba con sus excesos habituales.

Llegó a tal estado de gravedad que, según se dice, afirmó: "el administrador que me administraba, es incapaz de administrarme, así que no tiene sentido curar mi enfermedad". Esta expresión, señala su acuerdo con el viejo precepto hipocrático de no intervenir más al enfermo cuando ya no exista la posibilidad de su recuperación. Así. afirma en una de sus obras que el cuerpo del hombre debe llegar al fin natural de la vida, es decir, la muerte natural.

Finalmente, el llamado "príncipe de los médicos" murió en la ciudad de Hamadhan, donde fue sepultado, a mediados del año 1037 d. C. a los cincuenta y siete años de edad y en plena madurez de sus facultades intelectuales $\left({ }^{7}\right)$. pero la obra que le dio renombre universal fue el Canon de Medicina, que como ya se mencionó, sirvió de texto en muchas escuelas de oriente y occidente durante varios siglos ( $\left.{ }^{(.9}\right)$.

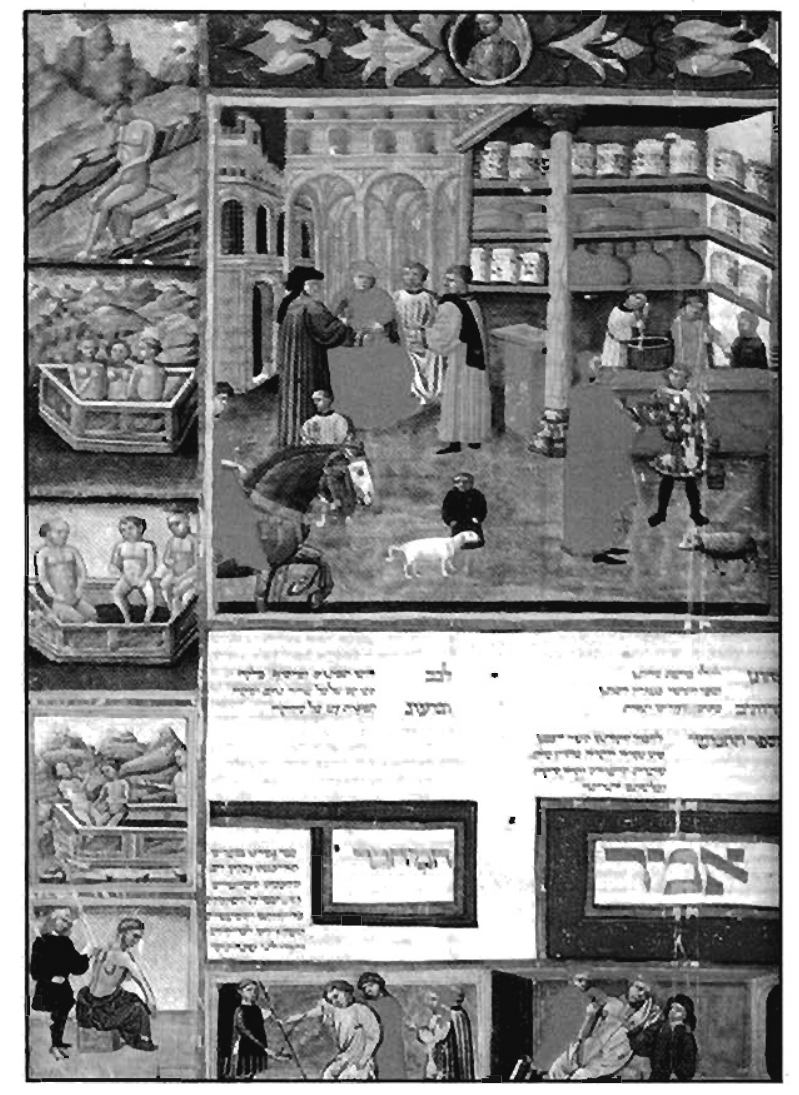

Página de un manuscrito hebreo del siglo XV del Canon de Avicena (Codice 2.197,

fol. 492 a -38 b) que se encuentra en la Biblioteca Universitaria de Bolonia.
El Canon es una obra que contiene todo el saber médico de su tiempo, incluyendo las tesis hipocrático-galénicas, junto con las observaciones y experiencias del propio Avicena y de otros médicos árabes. El Canon utiliza un sistema de clasificación que revela el interés del autor por presentar una obra fácil de asimilar.

Está constituido por cinco libros. En el primero, se hace una descripción general del cuerpo humano, sus temperamentos y facultades, causas y complicaciones de las enfermedades más comunes, higiene general, y el tema de la "necesidad de la muerte".

El segundo Libro, es una revisión de la "Materia médica" de Dioscórides, un médico griego cuya obra fue, durante quince siglos, la autoridad máxima en botánica aplicada a la medicina.

El tercer Libro contiene diferentes enfermedades regionales y el cuarto, enfermedades que afectan a todo el organismo.

\section{LA OBRA}

Avicena tuvo cierto gusto por la poesía y la música, de las que dejó algunos escritos. Sus vastos conocimientos en diversas disciplinas lo llevaron a escribir innumerables obras. Al-Mahdavi cita que escribió ciento cuarenta y dos títulos, entre ellos una enciclopedia que incluye astronomía, matemáticas, filosofía, erc.,
El quinto es una farmacopea muy completa que se refiere a la administración y composición de medicamentos, incluyendo muchos tratamientos originales de la medicina islámica que, según algunos autores, perduró en Europa hasta principios del siglo XIX.

Para Avicena la medicina es una teoría y una práctica donde ambas están en perfecto equilibrio. En el Canon, se desarrolla una cirugía paralela a una medicina 
sistemática. Establece que los desequilibrios humorales en los ventrículos causan enfermedad mental, que varía según su localización e intensidad. Hay trastornos parciales de la imaginación y la memoria, así como trastornos generales como la imbecilidad y la manía, las cuales tienen una génesis somática. Afirma que los problemas médicos son problemas de la ciencia natural ya que el objeto material de la medicina es el cuerpo humano y como sujeto formal la salud.

Dice que los procesos fisiológicos influyen en los procesos patológicos, por lo que no se puede establecer un límite claro entre lo normal y lo patológico, entre la salud y la enfermedad. Para demostrar su tesis, desarrolla el ejemplo de las repercusiones en el organismo de la actividad sexual nula o excesiva.

El médico, señala Avicena, "no es el que da la salud al enfermo, sino que solamente dispone, dejando actuar por si solas a las materias y los órganos". Aconsejaba beber aguas minerales y que se hicieran observaciones en animales para un mejor entendimiento de los fenómenos. Parece haberse dado cuenta de las propiedades antisépticas del alcohol, porque recomienda que las heridas primero se laven con vino $\left({ }^{5.6 .7}\right)$.

En el área de la química, quizá su mayor aportación fue desacreditar a la alquimia, práctica con cierto arraigo en el mundo islámico. Al respecto, señala que "Su posibilidad no es para mí evidente. La encuentro remo. ta porque no hay una manera de separar una combinación de otra... cuando la diferencia es desconocida. Y si una cosa es desconocida, ¿cómo puede ser posible tratar de producirla o destruirla?"

Para el manejo quirúrgico del cáncer, Avicena recomienda combatirlo en sus primeras etapas y extirpar todos los tejidos enfermos, como única esperanza de cura. También escribió el "Poema didáctico" que contiene mil trescientos trece versos que facilitaban el aprendizaje de la medicina. Así, el alumro podía aprender por un lado la teoría médica y, por otro, la práctica con el escalpelo, el medicamento o el consejo dietético.

No menos interesantes resultan las tesis de Avicena para la explicación causal de los fósiles animales y vegetales. Decía que la materia es inmutable y eterna. por lo mismo las especies ni nacen ni mueren, son inmutables. Los fósiles son el resultado de una "fuerza plástica" que por medio de los efectos de la "conglutinación y congelacion" originan formas caprichosas semejan- tes a plantas y animales. Llamaba conglutinación al proceso de transformación de la arcilla fina de las riberas en piedra blanda y congelación a la "solidificación del agua" en la formación de estalactitas y estalagmitas en las cavernas $\left({ }^{7}\right)$.

En el terreno de la filosofía, sobresale en su pensamiento la influencia del neoplatonismo y del aristotelismo. Creía que la verdad de las cosas no era asequible al hombre sólo con la razón, niega la resurrección corporal de los muertos como establece el Corán. En sus concepciones metafísicas (más allá del mundo físico), plantea que la existencia es sólo un accidente que se agrega a la esencia, es decir, que lo que percibimos de un objeto es algo secundario a lo que en realidad es $\left({ }^{8.9}\right)$.

Habla del "ser necesario" y del "ser posible". Al primero lo identifica con la divinidad al considerar que puede existir por sí mismo y es necesario en tanto que sólo él puede ser la causa de la existencia de los otros seres, los seres posibles, quienes, por lo tanto, no poseen en sí mismos la razón de su existir sino que la reciben del "ser necesario".

Un problema central de la metaética de Avicena, lo constituye la existencia del mal en el mundo, creado por el "ser necesario". Sin ser un moralista escribió una obra de ética "La buena obra y el mal" $\left({ }^{7}\right)$.

Su orientación no difiere de la de Aristóteles; sin embargo, tuvo interés de abordar el tema del mal. El mal tiene diversas formas -sostiene- es el resultado de un acto que provoca dolor o defecto que proviene de la ignorancia o de la deformación del cuerpo. También se deriva de aquello con que nos ha dotado la naturaleza para lograr la perfección. Sin embargo dice que la interacción entre el bien y el mal no es del todo inútil porque nos puede ser provechosa. El bien y el mal son relativos porque cambian según el punto de vista con que se les juzga.

Son interesantes sus conceptos sobre la muerte. Sustenta que es la separación del alma de sus relaciones con el cuerpo -difiriendo de Aristóteles y acercándose más al neoplatonismo-, cree que el cuerpo es mortal pero el alma no.

Observa que es la ignorancia lo que hace sentir temor por la muerte. No hay que condolerse por ella. porque si los hombres fueran inmortales, no podrían 
caber en el mundo. Por ello, según él, hay que considerar que la muerte es un acto de sabiduría divina $\left({ }^{5.9}\right)$.

Para Avicena la Lógica es un recurso para la inteligencia, que evita el error en lo que se afirma y se cree, conduciendo a la certeza cuando se dan razones y mélodos para alcanzarla.

\section{COMENTARIO FINAL}

Las obras de Avicena fueron traducidas del árabe por Domingo Gundisalvo en la ciudad de Toledo, España, alrededor del año 1180 d. C., con excepción del Canon de medicina que fue traducido por Gerardo de Cremona en ese mismo siglo.

Haly que señalar que algunos estudiosos de Avicena, principalmente anglo-sajones, han criticado su obra diciendo que el discurso del médico fílosofo está lleno de clasificaciones innecesarias. Dicen además que su stutus de autoridad académica limitó el progreso de la educación y de la práctica médica dentro del Islam durante mucho tiempo, de ahí que los médicos tuvieran menos libertad para pensar e interpretar sus propias observaciones, mutilando así su originalidad y creatividad $\left({ }^{10}\right)$.

Más que calificar una característica o consecuencia de la obra de un autor aisladamente, hay que analizar en principio, el contexto en el que se dio, es decir, las circunstancias espacio-temporales e históricas en que esa obra se produjo.

Desde mi punto de vista, coincidiría con Vasoli, en el sentido de aceptar que la obra de Avicena constituye "la primera gran síntesis especulativa florecida en el ámbito de la cultura clásica" $\left({ }^{9}\right)$ y cuya influencia contribuyó a la conservación y difusión de una buena parte del pensamiento grecolatino, fundamentalmente en $\mathrm{fi}$ losofía y medicina.

Por otra parte, la obra de Avicena es un ejemplo de lo que fueron los médicos durante muchos siglos después de surgida la medicina hipocrática hace dos mil quinientos años, una amalgama entre el que cura las enfermedades tratando de explicar los problemas de salud y el que reflexiona acerca de su entorno natural y social, como ser pensante. En suma, el médico-filósofo que nuestra sociedad actual debe rescatar y formar en sus universidades.

\section{BIBLIOGRAFÍA}

1) Ocampo MJ. El por qué de la Historia de la Medicina en la investigación médica (ensayo inédito) 1995.

2) Guerra r. Iberia and Latin America in The History of Medical Education. University of California Press. London. 1970.

3) Gibb AH. El Mahometismo. 2" Edicion. Fondo de Culıura Económica. México. 1966.

4) Martínez J. Persia-Islam. El Mundo Antiguo. Tomo V. SEP. México. 1984

5) Laín-Entralgo P. Historia de la Medicina. Salval. Barcelona. 1970.

6) Magner LA. A History of Medicine. Marcel Deckel. Inc. Ncw York. 1992.

7) Afnan FS. Avicena. his life and his works. George Allen \& Unwin Lid. Londres. 1958.

8) Parain B. Del mundo romano al Islam medioeval. Historia de la Filosofía. Tomo 3. $8^{2}$ Edición. Siglo XXI. México. 1990.

9) Reale G, Antiseri D. Historia del pensamiento filosófico y científico. Herder. Barcelona. 1988.

10) Hamarneh S. Medical Education and Practice in Medieval Islam in The History of Medical Education. University of California Press. London. 1970. 